\title{
Assessing the impact of acid rain and forest harvest intensity with the HD-MINTEQ model - soil chemistry of three Swedish conifer sites from 1880 to 2080
}

\author{
Eric McGivney $^{1, a}$, Jon Petter Gustafsson ${ }^{1,2}$, Salim Belyazid ${ }^{3}$, Therese Zetterberg ${ }^{4}$, and Stefan Löfgren ${ }^{5}$ \\ ${ }^{1}$ Department of Sustainable Development, Environmental Science and Engineering, \\ KTH Royal Institute of Technology, Teknikringen 10B, 10044 Stockholm, Sweden \\ ${ }^{2}$ Department of Soil and Environment, Swedish University of Agricultural Sciences, \\ P.O. Box 7014, 75007 Uppsala, Sweden \\ ${ }^{3}$ Department of Physical Geography, Stockholm University, 10691 Stockholm, Sweden \\ ${ }^{4}$ IVL Swedish Environmental Research Institute, \\ P.O. Box 53021, 40014 Göteborg, Sweden \\ ${ }^{5}$ Department of Aquatic Sciences and Assessment, Swedish University of Agricultural Sciences, \\ P.O. Box 7050, 75007 Uppsala, Sweden \\ ${ }^{a}$ current address: Department of Environmental Science and Analytical Chemistry \\ (ACES), Stockholm University, 10691 Stockholm, Sweden
}

Correspondence: Jon Petter Gustafsson (gustafjp@kth.se)

Received: 8 June 2018 - Discussion started: 20 June 2018

Revised: 11 December 2018 - Accepted: 18 January 2019 - Published: 5 February 2019

\begin{abstract}
Forest soils are susceptible to anthropogenic acidification. In the past, acid rain was a major contributor to soil acidification, but, now that atmospheric levels of S have dramatically declined, concern has shifted towards biomass-induced acidification, i.e. decreasing soil solution $\mathrm{pH}$ due to tree growth and harvesting events that permanently remove base cations (BCs) from forest stands. We use a novel dynamic model, HD-MINTEQ (Husby Dynamic MINTEQ), to investigate possible long-term impacts of two theoretical future harvesting scenarios in the year 2020, a conventional harvest ( $\mathrm{CH}$, which removes stems only), and a whole-tree harvest (WTH, which removes $100 \%$ of the above-ground biomass except for stumps) on soil chemistry and weathering rates at three different Swedish forest sites (Aneboda, Gårdsjön, and Kindla). Furthermore, acidification following the harvesting events is compared to the historical acidification that took place during the 20th century due to acid rain. Our results show that historical acidification due to acid rain had a larger impact on pore water chemistry and mineral weathering than tree growth and harvesting, at least if nitrification remained at a low level. However, compared to a no-harvest baseline, WTH and CH significantly impacted soil chemistry. Directly after a harvesting event (CH or WTH), the soil solution pH sharply increased for 5 to 10 years before slowly declining over the remainder of the simulation (until year 2080). WTH acidified soils slightly more than $\mathrm{CH}$, but in certain soil horizons there was practically no difference by the year 2080. Even though the $\mathrm{pH}$ in the WTH and CH scenario decreased with time as compared to the no-harvest scenario $(\mathrm{NH})$, they did not drop to the levels observed around the peak of historic acidification (1980-1990), indicating that the $\mathrm{pH}$ decrease due to tree growth and harvesting would be less impactful than that of historic atmospheric acidification. Weathering rates differed across locations and horizons in response to historic acidification. In general, the predicted changes in weathering rates were very small, which can be explained by the net effect of decreased $\mathrm{pH}$ and increased $\mathrm{Al}^{3+}$, which affected the weathering rate in opposite ways. Similarly, weathering rates after the harvesting scenarios in 2020 remained largely unchanged according to the model.
\end{abstract}


1

\section{Introduction}

Anthropogenic acidification has an impact on soils, streams, organisms, agriculture, and forestry. The acidification of soils is influenced by both vegetation growth and atmospheric deposition. During the 20th century, sulfur (S) deposition, which peaked in the 1980s, was the primary source of acidification in the acidic forest soils of the Northern Hemisphere (van Breemen et al., 1984). However, now that S deposition has dropped to around the 1930s level throughout Western Europe (Bertills et al., 2007; Engardt et al., 2017), focus has shifted towards understanding forest soil dynamics in response to forest biomass production and different harvesting scenarios (Akselsson et al., 2007; Iwald et al., 2013; de Jong et al., 2017).

Tree growth acidifies the soil through the net uptake of cations over anions, which results in an accumulation of $\mathrm{H}^{+}$ in the form of organic acids (Nilsson et al., 1982). Forests that are recurrently harvested for lumber and paper production are especially susceptible to biomass-induced acidification, such as those in northern Europe. Mass balance calculations show considerable losses of base cations $\mathrm{Ca}^{2+}$, $\mathrm{Mg}^{2+}, \mathrm{Na}^{+}$, and $\mathrm{K}^{+}$(BCs) due to forest management practices, which may have strong acidifying effects on soils of base-poor mineralogy (Akselsson et al., 2007; Iwald et al., 2013). Therefore, there is a need to develop sustainable forestry practices in which the net losses of BCs are minimized to avoid acidification and long-term depletion of BCs (Vadeboncoeur et al., 2014).

Models that can accurately predict forest soil chemistry based on uptake trends, plant growth, mineral weathering, harvesting scenarios, and deposition rates are powerful in assessing the susceptibility of soils to biomass-induced acidification. Dynamic soil chemistry models such as MAGIC (Cosby et al., 1985, 2001) and ForSAFE (Wallman et al., 2005) have been used in the past, where both models were applied to Swedish forest stands. Due to historic data collection and well-documented forestry practices, Swedish forests provide an excellent setting to develop and validate such models. For example, Belyazid et al. (2006) used ForSAFE to simulate changes in soil chemistry relative to atmospheric deposition at 16 different forest sites across Sweden and showed that enhanced tree growth due to elevated nitrogen deposition could delay or even reverse the recovery of soils from acidification caused by the historical acid deposition. In another study, Zetterberg et al. (2014) used MAGIC to simulate changes in soil $\mathrm{Ca}^{2+}$ pools and stream acid neutralizing capacity at multiple harvest scenarios for three different Swedish forest stands. In a complementing study, based on data from three Swedish experimental sites with stemonly and whole-tree harvest (WTH) treatments, it was found that MAGIC exaggerated the $\mathrm{Ca}^{2+}$ loss due to harvesting between 1990 and 2013 (Zetterberg et al., 2016).
The objectives of this paper are to (i) investigate possible long-term impacts of two theoretical future harvesting scenarios on the acidification and base cation status using a novel dynamic model, HD-MINTEQ (Husby Dynamic MINTEQ), and (ii) compare biomass-induced acidification to the historical acidification that took place during the 20th century due to acid rain. Specifically, we describe the soil chemical dynamics of three different Swedish forest stands - Aneboda, Gårdsjön, and Kindla - using HDMINTEQ (Löfgren et al., 2017) for the period 1880-2080.

An advantage of using the HD-MINTEQ model over, for example, ForSAFE and MAGIC is that the former is based on state-of-the-art descriptions of aluminium $(\mathrm{Al})$ and base cation chemistry, which are probably more accurate (Gustafsson et al., 2018). The version used in this paper incorporates the $\mathrm{BC}$ release kinetics from the PROFILE weathering model (Sverdrup and Warfvinge, 1993).

In the following, we first use historical data to model the soil chemistry dynamics from 1880 through 2080 assuming that there are no harvesting events in the future. Modelled results are compared to measured soil water data for the period 1993 to 2010. Next we modelled the effects of two different harvesting intensities in 2020: conventional harvest $(\mathrm{CH})$, which removes stems only, and a whole-tree harvest, which in addition to stems also removes tops and branches. The parameters in focus are soil solution $\mathrm{pH}$, soil solution $\mathrm{BC}$ concentration, $\mathrm{Ca}^{2+}$ sorption, and weathering rates.

\section{Methods}

\subsection{HD-MINTEQ}

Simulations were run using the Husby Dynamic MINTEQ model (HD-MINTEQ), which connects the equilibrium calculations of Visual MINTEQ version 3.1 (Gustafsson, 2018); the simple mass balance model (Sverdrup and De Vries, 1994); and the PROFILE model for soil chemical weathering (Sverdrup and Warfvinge, 1993). The details of HDMINTEQ have previously been described by Löfgren et al. (2017) and in a companion paper by Gustafsson et al. (2018). In brief, it relies on the Stockholm Humic Model (SHM) for organic complexation (Gustafsson, 2001; Gustafsson and Kleja, 2005). The model assumes that the equilibria for ferrihydrite and $\mathrm{Al}(\mathrm{OH})_{3}$ provide the upper limit for the solubility of $\mathrm{Fe}^{3+}$ and $\mathrm{Al}^{3+}$ in mineral soil horizons. Further, it uses an extended Freundlich model to simulate $\mathrm{SO}_{4}$ adsorption (Gustafsson et al., 2015). HD-MINTEQ does not simulate $\mathrm{N}$ chemistry; instead dissolved $\mathrm{NH}_{4}^{+}$and $\mathrm{NO}_{3}^{-}$in the different horizons are given as input data and are held constant (Table 1). The soil pools of organic C and geochemically active Al were assumed to be constant over the simulated time period. To deal with water transport, HD-MINTEQ uses a 1-D advective-dispersive equation, although the actual dispersion is often governed by the thick- 
ness of the modelled soil layers. Vertical flow is assumed, which should be a reasonable approximation for the studied soils, as they were located in recharge areas where the soil surface was nearly flat. The plant uptake is distributed over the two or three uppermost layers, as in the SAFE model of Warfvinge et al. (1993).

\subsection{Model setup}

In the current application of the HD-MINTEQ model, the soils were compartmentalized into four different discrete horizons: an organic horizon (O), an eluvial layer (E), and two illuvial subsoil horizons (B1 and B2). Simulations were run over a 200-year period from 1880 to 2080, with a 1-week time step. Three different forest stands were simulated Aneboda $\left(57^{\circ} 05^{\prime} \mathrm{N} 12^{\circ} 32^{\prime} \mathrm{E}\right)$, Gårdsjön $\left(58^{\circ} 40^{\prime} \mathrm{N} 12^{\circ} 30^{\prime} \mathrm{E}\right)$, and Kindla $\left(59^{\circ} 05^{\prime} \mathrm{N} 12^{\circ} 01^{\prime} \mathrm{E}\right)$ (Fig. S1 in the Supplement) - under three different harvest scenarios:

1. conventional harvest (stem-only removal),

2. whole-tree harvest (100\% removal of above-ground logging residues), and

3. no-harvest control (NH).

At all three cites, the harvest events occurred in the year 2020.

The input data for each site and soil horizon are presented in Table 1 and were based on climate and soil profile (Podzol) data collected in earlier work. For the most part, these are given in Löfgren et al. (2011). The bulk densities were estimated as a function of organic $\mathrm{C}$ and soil depth using the empirical relationships of Nilsson and Lundin (2006). The volumetric water content was set to a common value of $0.3 \mathrm{~m}^{3} \mathrm{~m}^{-3}$. The extent of sulfate adsorption in the B1 horizon of Kindla was assumed to be strongly sorbing ("strong" in Table 1), similar to that of another Podzol in the same area of Sweden (Gustafsson et al., 2015). The other two soils from south-western Sweden were assumed to have less (Table 1) sulfate adsorption, in agreement with other soils from this area (Karltun, 1995); the relevant Freundlich parameters were taken from the Tärnsjö soil of Gustafsson et al. (2015). The mineral soil horizons were assumed to be in equilibrium with ferrihydrite, whereas $\mathrm{Fe}$ (III) was assumed to be negligible in the O horizons. Dissolved organic C (DOC) was assumed to be constant throughout the simulation period, and the values were calculated from the mean DOC concentrations in soil solution (lysimeter data) between 1993 and 2014.

\subsection{Deposition}

Historical wet deposition data for the three sites (Fig. S2) were taken from Löfgren et al. (2011) and from Zetterberg et al. (2014). To calculate the contribution from dry deposition, results from measurements of a surrogate surface were used (Ferm and Hultberg, 1995, 1999). Reductions of the total deposition as a result of harvesting were considered using functions of Zetterberg et al. (2014). CH and WTH scenarios used the same deposition profiles, represented by the dotted lines in Fig. S2. In the NH scenario, deposition values were maintained at 2019 levels from 2020 through 2080. The relatively high levels of $\mathrm{Na}$ and $\mathrm{Cl}$ deposition at Gårdsjön were due to its proximity to the sea. The dips in deposition at Gårdsjön in the early 1900s and Kindla around 1890 were due to historical harvesting events. The dips that occur in 2020 were due to the simulated harvest scenarios. Following the rise and fall of $\mathrm{SO}_{4}$ throughout the 20th century (grey shaded and labelled "historical acidification") at all three sites, the influence of industrial emissions and subsequent regulations can be clearly seen. Currently, the $\mathrm{SO}_{4}$ deposition is similar to the levels observed in the 1930s.

\subsection{Plant uptake}

BC uptake trends at Kindla and Aneboda (Fig. S3) were calculated as described previously (Zetterberg et al., 2014). Briefly, biomass at any given time point was used to allocate the cation amount over time according to classical growth curves and information regarding any natural event (e.g. storms and fire) or silvicultural measures (e.g. clearcutting and thinning) that have taken place during the rotation period. The final uptake curves were created by multiplying the biomass increments by the nutrient concentrations for various tree parts. BC uptake rates are based on current biomass (hindcast scenario) and future biomass predictions by the Swedish forest growth model ProdMod, version 2.2 (Ekö, 1985). BC uptake values were finally corrected for litterfall (which returns $\mathrm{BCs}$ to the soil) and remineralization estimates. The net BC uptake at Gårdsjön was estimated using the ForSAFE model, by dynamically simulating photosynthesis, growth, and gross uptake in response to environmental drivers and subtracting litterfall that was physiologically simulated in response to light saturation, respiration, and water availability (Belyazid and Moldan, 2009).

The highest rates of net uptake occur in young growing forests, and as the forest stands age, less BCs are taken up. The stack of graphs in the left column of Fig. S3 represents the NH scenario, which means that for Aneboda and Kindla, uptake trends after 2019 were modelled using an exponential decay and essentially approach zero as time goes on. The stack of graphs in the central and right columns (Fig. S3) represents the uptake trends that were used from 2020 and onwards under the $\mathrm{CH}$ and WTH scenarios, respectively. The negative values in uptake that occur after harvesting events are due to net influx of $\mathrm{BCs}$ originating from mineralization of leftover debris. The $\mathrm{CH}$ scenarios produce more negative values than WTH scenarios because there is more debris left on the soil. It should also be noted that the assumed $100 \%$ removal of harvest residuals in the WTH scenario is an over- 
Table 1. Parameter values and assumptions used for the HD-MINTEQ simulations of all three sites.

\begin{tabular}{|c|c|c|c|c|c|c|c|c|c|c|c|c|}
\hline \multirow{2}{*}{$\begin{array}{l}\text { Site } \\
\text { Horizon }\end{array}$} & \multicolumn{4}{|c|}{ Aneboda } & \multicolumn{4}{|c|}{ Gårdsjön } & \multicolumn{4}{|c|}{ Kindla } \\
\hline & $\mathrm{O}$ & $\mathrm{E}$ & Bs1 & Bs2 & $\mathrm{O}$ & $\mathrm{E}$ & Bs1 & Bs2 & $\mathrm{O}$ & $\mathrm{E}$ & Bs1 & Bs2 \\
\hline Thickness (m) & 0.1 & 0.1 & 0.15 & 0.15 & 0.05 & 0.05 & 0.2 & 0.15 & 0.1 & 0.1 & 0.15 & 0.15 \\
\hline Bulk density $\left(\mathrm{kg} \mathrm{m}^{-3}\right)$ & 118 & 837 & 980 & 1122 & 156 & 773 & 749 & 836 & 118 & 1004 & 980 & 1237 \\
\hline Volumetric water content $\left(\mathrm{m}^{3} \mathrm{~m}^{-3}\right)$ & 0.3 & 0.3 & 0.3 & 0.3 & 0.3 & 0.3 & 0.3 & 0.3 & 0.3 & 0.3 & 0.3 & 0.3 \\
\hline Dispersivity (m) & 0.01 & 0.01 & 0.01 & 0.01 & 0.01 & 0.01 & 0.01 & 0.01 & 0.01 & 0.01 & 0.01 & 0.01 \\
\hline Discharge $(\mathrm{mm})$ & 500 & 400 & 350 & 350 & 550 & 500 & 450 & 450 & 600 & 500 & 450 & 450 \\
\hline Winter soil temp $\left({ }^{\circ} \mathrm{C}\right)$ & 3 & 4 & 6 & 8 & 3 & 4 & 6 & 8 & 3 & 4 & 5 & 6 \\
\hline Summer soil temp $\left({ }^{\circ} \mathrm{C}\right)$ & 12 & 11 & 9 & 8 & 12 & 11 & 9 & 8 & 10 & 8 & 7 & 6 \\
\hline Dissolved $\mathrm{NH}_{4}^{+}(\mu \mathrm{M})$ & 14 & $14^{\mathrm{a}}$ & $5.5^{\mathrm{a}}$ & $5.5^{\mathrm{a}}$ & 0.5 & 2.6 & 4.2 & 4.2 & 0.5 & 2.9 & 3.9 & 3.9 \\
\hline Dissolved $\mathrm{NO}_{3}^{-}(\mu \mathrm{M})$ & 0.5 & $0.5^{\mathrm{a}}$ & $0.3^{\mathrm{a}}$ & $0.3^{\mathrm{a}}$ & 0.5 & 0.4 & 0.4 & 0.4 & 0.5 & 0.3 & 0.5 & 0.5 \\
\hline Organic C $(\%)^{3}$ & 40 & 4 & 2.5 & 1.5 & 40 & 5 & 6 & 5 & 40 & 2 & 2.5 & 0.8 \\
\hline Sulfate adsorption & no & no & no & some & no & no & some & some & no & no & strong & some \\
\hline Equilibrium with ferrihydrite & no & yes & yes & yes & no & yes & yes & yes & no & yes & yes & yes \\
\hline Geochemically active $\mathrm{Al}\left(\mathrm{mmol} \mathrm{kg}^{-1}\right)$ & 30 & 40 & 40 & 30 & 40 & 50 & 100 & 121 & 30 & 15 & 60 & 60 \\
\hline Partial $\mathrm{CO}_{2}$ pressure (atm) & 0.001 & 0.003 & 0.007 & 0.01 & 0.001 & 0.002 & 0.007 & 0.01 & 0.001 & 0.002 & 0.007 & 0.01 \\
\hline $\operatorname{DOC}\left(\mathrm{mg} \mathrm{L}^{-1}\right)$ & 50 & 48.5 & 7.7 & 7.7 & 35 & 12.6 & 9.8 & 9.8 & 25 & 13.7 & 3.7 & 3.7 \\
\hline Base cation uptake (\% of total) & 20 & 50 & 30 & 0 & 50 & 30 & 20 & 0 & 20 & 50 & 30 & 0 \\
\hline Start of growth period (week of the year) & 15 & 15 & 15 & 15 & 15 & 15 & 15 & 15 & 20 & 20 & 20 & 20 \\
\hline Duration of growth period (weeks) & 30 & 30 & 30 & 30 & 30 & 30 & 30 & 30 & 20 & 20 & 20 & 20 \\
\hline \multicolumn{13}{|l|}{ Mineral composition } \\
\hline K feldspar $100(\%)$ & 5.76 & 5.76 & 7.52 & 14.11 & - & - & - & - & 12.20 & 12.20 & 10.75 & 10.74 \\
\hline $\mathrm{K}$ feldspar $(\%)$ & - & - & - & - & - & 15.0 & 18.0 & 19.0 & - & - & - & - \\
\hline Plagioclase (\%) & - & - & - & - & - & 14.0 & 15.0 & 16.0 & - & - & - & - \\
\hline Anorthite (\%) & 3.62 & 3.63 & 2.24 & 4.20 & - & - & - & - & 1.63 & 1.63 & 0.64 & 1.10 \\
\hline Albite $(\%)$ & 22.41 & 22.41 & 25.69 & 27.49 & - & - & - & - & 27.81 & 27.81 & 21.22 & 23.08 \\
\hline Hornblende (\%) & 1.11 & 1.11 & 1.01 & 1.62 & - & 0.1 & 1.5 & 1.5 & 1.76 & 1.76 & 0.33 & 0.95 \\
\hline Epidote $(\%)$ & 4.56 & 4.56 & 4.07 & 4.13 & - & 0.1 & 0.75 & 1.0 & 2.14 & 2.14 & 0.61 & 1.30 \\
\hline Garnet $(\%)$ & - & - & - & - & - & 0.1 & 0.1 & 0.1 & - & - & - & - \\
\hline Biotite $(\%)$ & - & - & - & - & - & 0.5 & 0.5 & 0.5 & - & - & - & - \\
\hline Apatite $(\%)$ & 0.09 & 0.09 & 0.24 & 0.24 & - & 0.1 & 0.2 & 0.3 & 0.21 & 0.21 & 0.09 & 0.15 \\
\hline Fe-Chlorite (\%) & & & & & - & 0.4 & 0.4 & 0.4 & - & - & - & - \\
\hline Chlorite (\%) & 0.50 & 0.50 & 0.40 & 0.88 & - & - & - & - & 0.81 & 0.81 & 0.19 & 0.33 \\
\hline Illite1 (\%) & 2.07 & 2.07 & 3.53 & 1.77 & - & - & - & - & 1.43 & 1.43 & 1.24 & 4.35 \\
\hline Mg-Vermiculite (\%) & - & - & - & - & - & 3.0 & 15.0 & 5.0 & - & - & - & - \\
\hline Vermiculite $1(\%)$ & 1.21 & 1.21 & 2.16 & 2.78 & - & - & - & - & 1.64 & 1.64 & 0.48 & 0.84 \\
\hline Vermiculite $2(\%)$ & 0.50 & 0.50 & 0.38 & 0.84 & - & - & - & - & 0.99 & 0.99 & 0.16 & 0.31 \\
\hline Muscovite (\%) & 6.92 & 6.92 & 10.67 & 3.65 & - & - & - & - & 1.56 & 1.56 & 1.36 & 8.06 \\
\hline Rutile $(\%)$ & 0.56 & 0.56 & 0.49 & 0.49 & - & - & - & - & - & - & 0.21 & 0.28 \\
\hline Hematite (\%) & 2.33 & 2.33 & 0.73 & 0.73 & - & - & - & - & 0.43 & 0.43 & 0.08 & 2.11 \\
\hline Chlorite1 (\%) & 0.73 & 0.73 & 0.63 & 1.72 & - & - & - & - & 1.35 & 1.35 & 0.33 & 0.49 \\
\hline Specific surface area $\left(\mathrm{m}^{2} \mathrm{~g}^{-1}\right)$ & 1.14 & 1.04 & 0.95 & 0.95 & - & 1.2 & 1.1 & 1.98 & - & 1.29 & 1.18 & 1.18 \\
\hline
\end{tabular}

a These values were adjusted for calibration to account for elevated $\mathrm{N}$ concentrations detected in lysimeter data from 2011 onwards. This was due to storm damage (Gudrun) in the region, which brought down many trees in 2005.

estimation; in practice, $\sim 70 \%$ is removed (Nilsson et al., 2015).

\subsection{Mineralogy and weathering}

For Aneboda and Kindla, the mineralogy used in the PROFILE submodel was calculated from data on total elemental analysis using the A2M model (Posch and Kurz, 2007). For Gårdsjön, the mineralogy was taken directly from Martinson et al. (2003). The specific surface area used by PROFILE was estimated from the particle-size distribution using the relationship of Sverdrup (1996). The mineralogy data are presented in Table 1. To calculate weathering rates, the rela- tionships of Sverdrup and Warfvinge (1993) were used. The only modification in the current work was the way in which the organic anion concentrations $\left[R^{-}\right]\left(\mathrm{molL}^{-1}\right)$ were calculated, as HD-MINTEQ uses the SHM, whereas the original PROFILE model used the Oliver equation. Thus, the main equation to calculate the weathering rate is

$r=k_{\mathrm{H}^{+}} \cdot \frac{\left\{\mathrm{H}^{+}\right\}^{n}}{f_{\mathrm{H}}}+\frac{k_{\mathrm{H}_{2} \mathrm{O}}}{f_{\mathrm{H}_{2} \mathrm{O}}}+k_{\mathrm{CO}_{2}} \cdot P_{\mathrm{CO}_{2}}^{n_{\mathrm{CO}_{2}}}+k_{R} \cdot \frac{\left[R^{-}\right]^{n_{R}}}{f_{R}}$,

where $r$ is the weathering rate $\left(\mathrm{keq} \mathrm{m}^{-2} \mathrm{~s}^{-1}\right)$ for an individual mineral; $k_{\mathrm{H}^{+}}, k_{\mathrm{H}_{2} \mathrm{O}}$, and $k_{R}$ are the rate coefficients for the reaction with $\mathrm{H}^{+}, \mathrm{H}_{2} \mathrm{O}$, and DOC, respectively $\left(\mathrm{m} \mathrm{s}^{-1}\right) ; n_{\mathrm{H}}$, 
$n_{\mathrm{CO}_{2}}$, and $n_{R}$ are the reaction orders of individual reactions; $P_{\mathrm{CO}_{2}}$ is the partial $\mathrm{CO}_{2}$ pressure (atm); and $f_{\mathrm{H}}, f_{\mathrm{H}_{2} \mathrm{O}}$, and $f_{R}$ are the retardation factors ("brakes"). The latter are defined as

$$
\begin{aligned}
f_{\mathrm{H}} & =\left(1+\frac{\left[\mathrm{Al}^{3+}\right]}{k_{\mathrm{Al}}}\right)^{x_{\mathrm{Al}}} \\
& \cdot\left(1+\frac{2\left[\mathrm{Ca}^{2+}\right]+2\left[\mathrm{Mg}^{2+}\right]+\left[\mathrm{K}^{+}\right]+\left[\mathrm{Na}^{+}\right]}{k_{\mathrm{BC}}}\right)^{x_{\mathrm{BC}}}, \\
f_{\mathrm{H}_{2} \mathrm{O}} & =\left(1+\frac{\left[\mathrm{Al}^{3+}\right]}{k_{\mathrm{Al}}}\right)^{z_{\mathrm{Al}}} \\
& \cdot\left(1+\frac{2\left[\mathrm{Ca}^{2+}\right]+2\left[\mathrm{Mg}^{2+}\right]+\left[\mathrm{K}^{+}\right]+\left[\mathrm{Na}^{+}\right]}{k_{\mathrm{BC}}}\right)^{z_{\mathrm{BC}}} \\
f_{R} & =1+\left(\frac{\left[R^{-}\right]}{k_{R}}\right)^{0.5},
\end{aligned}
$$

where $k_{\mathrm{Al}}, k_{\mathrm{BC}}$, and $k_{R}$ are saturation coefficients for dissolution reductions, whereas $x_{\mathrm{Al}}, x_{\mathrm{BC}}, z_{\mathrm{Al}}$, and $z_{\mathrm{BC}}$ are reaction orders. Values of all coefficients and reaction orders were taken from Sverdrup and Warfvinge (1993).

\subsection{Calibration}

To initialize the model, dissolved concentrations of major cations, anions, and DOC were provided for the first time step (in 1880) and for the solid-phase geochemically active $\mathrm{Al}$ (Table 1). Based on this input, HD-MINTEQ then calculated the start $\mathrm{pH}$ and the corresponding sorbed concentrations of major ions as well as dissolved $\mathrm{Al}$.

The model was calibrated in an iterative process in which geochemically active $\mathrm{Al}$ and the plant uptake percentages of the different layers were adjusted. Further, it was assumed that the soil water chemistry was in a steady state with respect to the environmental conditions in 1880 , i.e. with respect to the assumed values for atmospheric deposition, plant uptake, weathering, etc. Before calibration, an initial guess was made of geochemically active $\mathrm{Al}$ and of the base cation uptake percentages. During each iteration, the first step was to run the model for 1000 years with the 1880 parameters to obtain initial (start-state) values of dissolved ions. Final values produced after a 1000-year simulation were then used to initiate the model, which was rerun with historical disturbances and changes in atmospheric deposition. The modelled values of $\mathrm{pH}$, dissolved inorganic $\mathrm{Al}$, and other $\mathrm{BC}$ concentrations from 1993 to 2014 were then compared to soil solution data from the same period taken from various depths and binned into either horizon E or B before being plotted (Löfgren et al., 2011). Further, it was checked that the assumed BC uptake percentages did not result in uneven depletion rates in the different layers; if so, the percentages were adjusted. Based on the above, refined guesses of geochemically active $\mathrm{Al}$ and of the plant uptake distribution could be made for the next iteration.

During the initial model runs, it was found that the modelled drop in pH after 2020 at Aneboda and Kindla was limited by the amount of sorbed $\mathrm{Ca}^{2+}$, restricting $\mathrm{Ca}^{2+}$ available for vegetation uptake. In the harvesting scenarios the sorbed $\mathrm{Ca}^{2+}$ pool was not replenished in spite of the increased $\mathrm{pH}$ after historic acidification, which is similar to what was observed in the MAGIC simulations of Zetterberg et al. (2014). This in turn led to extremely low levels of dissolved $\mathrm{Ca}^{2+}$ and to occasional model errors due to negative concentrations in preliminary model runs. To stop this from happening, the net $\mathrm{Ca}^{2+}$ uptake was decreased as dissolved $\mathrm{Ca}^{2+}$ decreased, according to the following relationships taken from the "old" SAFE model (Alveteg, unpublished):

$\mathrm{Ca}_{\text {upt, real }}=f_{\text {upt }} \cdot \mathrm{Ca}_{\text {upt, init }}$,

where $\mathrm{Ca}_{\text {upt,real }}$ is the adjusted net $\mathrm{Ca}$ uptake, $\mathrm{Ca}_{\text {upt,init }}$ is the assumed $\mathrm{Ca}$ uptake according to Table 1 , and $f_{\text {upt }}$ is defined by

$f_{\text {upt }}=\frac{\left[\mathrm{Ca}^{2+}\right]^{n}}{\left[\mathrm{Ca}^{2+}\right]^{n}+c^{n}}$,

where $n=4$ and $c=1.5 \times 10^{-6}$. These equations prevented dissolved $\mathrm{Ca}^{2+}$ concentrations from falling below $5 \mu \mathrm{molL} \mathrm{L}^{-1}$, but they also limited the acidification effect due to Ca uptake. To what extent trees will adjust their BC uptake in response to lower availability in the soil is still debated (Zetterberg et al., 2014). In plot experiments in which the effects of harvesting were studied, the depletion of sorbed $\mathrm{Ca}^{2+}$ was less severe than that predicted by mass balance calculations and models (Zetterberg et al., 2014). Possible reasons include both a lower $\mathrm{Ca}^{2+}$ uptake to trees and mineralization of strongly bound $\mathrm{Ca}^{2+}$ in litter, which is otherwise not geochemically active. However, because the HDMINTEQ simulations here produced stronger effects on soil Ca compared to those observed in the field (Zetterberg et al., 2016), it seems probable that the acidification effect as predicted by HD-MINTEQ may be regarded as a worst-case scenario and that the real acidification, at least over the first rotation period, may be even smaller. However, at this point it needs to be added that these conclusions may not be relevant in cases when nitrification following harvest is substantial, in which case the acidification effect could be considerably larger; this possibility was not considered in our simulations. Most Swedish forests are N limited (Högberg et al., 2017), but increased nitrate concentrations are found in soil solution for some years after final felling. Nitrification is dependent on site productivity, which is between 4 and $8 \mathrm{~m}^{3} \mathrm{ha}^{-1} \mathrm{yr}^{-1}$ in the sites studied. According to the estimates of Futter et al. (2010), the total accumulated harvest effect should generally not exceed 220 and 500 meq $\mathrm{NO}_{3}^{-} \mathrm{m}^{-2}$ for site productivities of 4 and $8 \mathrm{~m}^{3} \mathrm{ha}^{-1} \mathrm{yr}^{-1}$, respectively (Futter et al., 2010), indicating rather modest nitrification effects on the 
long-term acid-base status of the soils. As an example, this value represents between $5 \%$ and $15 \%$ of the atmospherically deposited BCs over a full rotation period; hence nitrification is a relatively minor proton source as compared to other processes in the forest soils under study.

\section{Results and discussion}

\subsection{Historic acidification}

Historic acidification of forest soils from atmospheric deposition of S took place from 1940 through 2000 and can be seen in the modelled soil solution $\mathrm{pH}$ profiles at Aneboda (Fig. 1a), Gårdsjön (Fig. 2a), and Kindla (Fig. 3a). At Aneboda, the lowest soil solution $\mathrm{pH}$ for each horizon occurred around 1990, about the same time that atmospheric S deposition began to decline (Fig. S2). The most dramatic decrease in $\mathrm{pH}$ at Aneboda occurred within the B1 horizon, dropping from $\mathrm{pH} 5.29$ in 1940 to $\mathrm{pH} 4.81$ in the late 1980s, a total $\mathrm{pH}$ decline of 0.48 units in 47 years. The other horizons $(\mathrm{O}, \mathrm{E}$, and $\mathrm{B} 2)$ at Aneboda saw milder changes in $\mathrm{pH}$ $(<0.20$ units) over the same time period. The effects of historical acid rain can also be seen in the $\mathrm{BC}$ profiles of $\mathrm{Ca}^{2+}$ and $\mathrm{Mg}^{2+}$, most significantly in the $\mathrm{B} 1$ and $\mathrm{B} 2$ horizons of Aneboda. An increase in dissolved BCs occurred in order to balance the charge created by increasing levels of anions $\left(\mathrm{SO}_{4}^{2-}\right.$ and $\mathrm{NO}_{3}^{-}$) being deposited from the atmosphere; i.e. these $\mathrm{BCs}$ were exchangeable and responsive to anion concentrations. Between 1940 and 1980, dissolved $\mathrm{Ca}^{2+}$ concentrations increased by $275 \%$ and $94 \%$ in the B1 and B2 horizon, respectively. The anomalous blip in $\mathrm{pH}$ (and $\mathrm{BCs}$ ) at Aneboda occurring between 2008 and 2018 is the result of a large storm that downed many trees in 2005 , followed by a bark beetle infestation, resulting in mineralization, acidification, and increased dissolved $\mathrm{Ca}^{2+}$ (Löfgren et al., 2014).

Of the three sites studied, the strongest effect of historic acid rain was seen at Gårdsjön (Fig. 2a), which experienced an average decline of $0.39 \mathrm{pH}$ units across all four horizons. This is likely due to the higher $\mathrm{S}$ (as sulfuric acid) deposition at Gårdsjön (Fig. S2). The horizon subject to the most drastic acidification was the $\mathrm{E}$ horizon, which experienced a sharp decline from $\mathrm{pH} 4.81$ in 1940 to $\mathrm{pH} 4.02$ by 1985 (a drop of $0.70 \mathrm{pH}$ units in 45 years). Similar to Aneboda, Gårdsjön experienced its most acidic soil conditions in the mid 1980s. However, the B1 horizon did see a slight delay, experiencing its most acidic conditions in the early 1990s. This trend in delayed acidification across horizons was even more pronounced at Kindla (Fig. 3a), where the $\mathrm{O}$ and $\mathrm{E}$ horizons reached their most acidic conditions by 1980 , the B1 horizon continued to acidify until 1994, and the B2 horizon did not reach its most acidic conditions until 2013 (nearly 25 years after the $\mathrm{S}$ and $\mathrm{N}$ deposition began to decline, Fig. S2). The delayed response was mainly attributed to $\mathrm{SO}_{4}$ adsorption and desorption, which is known to delay response times to decades for strongly $\mathrm{SO}_{4}$-adsorbing soil systems (Cosby et al., 1986).

The dissolved aluminium profiles at all three sites show that most of the mobilization of dissolved $\mathrm{Al}$ occurred in the E horizon. This was likely due to the higher $\mathrm{pH}$ of the $\mathrm{B}$ horizons ( $\mathrm{pH}>5$ ), where the precipitation of aluminium hydroxide and/or allophane removed soluble $\mathrm{Al}$ (Gustafsson et al., 1995; Karltun et al., 2000). This inverse relationship with $\mathrm{pH}$ is demonstrated clearly for Kindla's B1 horizon, where soluble $\mathrm{Al}$ concentration peaked as $\mathrm{pH}$ decreased below 5 (Fig. 3). The low levels of soluble $\mathrm{Al}$ in the $\mathrm{O}$ horizon are attributed to complexation with organic ligands.

For the Gårdsjön and Kindla sites, the modelled results align well with the lysimeter data, with a few exceptions. Interestingly, the model underestimated $\mathrm{Mg}^{2+}$ concentrations at both sites. This could be caused by the use of A2M estimates, i.e. that the normalization model underestimated the presence of easily weathered Mg-containing minerals. In a recent study, Casetou-Gustafson et al. (2018) compared A2M with the mineralogy obtained by X-ray powder diffraction (XRPD) for two soils that were similar to the soils studied here. They found that trioctahedral mica and hydrobiotite were consistently underestimated by $\mathrm{A} 2 \mathrm{M}$, which is consistent with our modelling results as these Mg-containing minerals have relatively high weathering rates. Moreover at Kindla, $\mathrm{SO}_{4}^{2-}$ concentrations were underestimated. There may be several explanations, but one possibility is mineralization and oxidation of organically bound $\mathrm{S}$ (Löfgren et al., 2001, 2014). The delay in $\mathrm{SO}_{4}^{2-}$ decrease at Kindla was, however, predicted well in the B1 horizon of the model.

For the Aneboda site, the discrepancies between model and observations were more substantial. For example, while $\mathrm{SO}_{4}^{2-}$ and $\mathrm{pH}$ were grossly underestimated, $\mathrm{Ca}^{2+}$ and $\mathrm{Mg}^{2+}$ were overestimated. It is important to note that the lysimeter data plotted in Figs. 1, 2, and 3 are averages based on data from several lysimeters, and it has previously been observed that there are large variations in the results of individual lysimeters at the Aneboda site (Löfgren et al., 2010, 2011, 2014). As an example, for the B horizon the averaged results are based on eight lysimeters. Three of these, nos. 7102, 7104 , and 7105 , had results that were clearly divergent from the others (Fig. S4). Dissolved $\mathrm{SO}_{4}^{2-}, \mathrm{Ca}^{2+}$, and $\mathrm{Mg}^{2+}$ were all considerably higher, whereas the $\mathrm{pH}$ was lower. Possible reasons include a net mineralization and oxidation of organically bound sulfur in response to decreased $\mathrm{S}$ deposition (Löfgren et al., 2001, 2014), a process which was not taken into account in the model. It may also be observed that if the results from the three lysimeters were removed, there would be a clearly improved agreement between the model and the observations.

\subsection{Harvesting-induced acidification}

One trend across all horizons at all sites was that, directly after a simulated harvesting event $(\mathrm{CH}$ or WTH) in 2020, the 

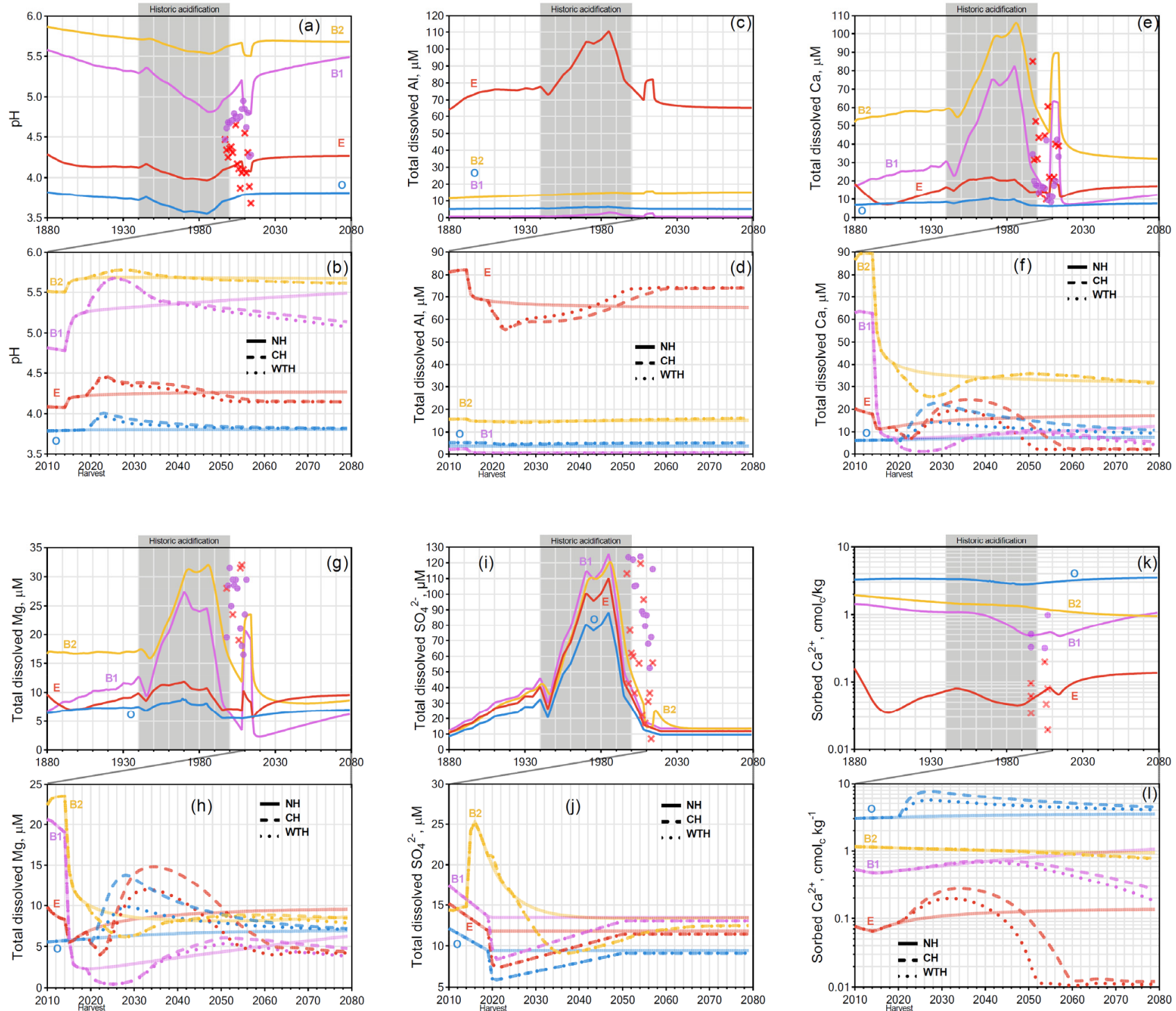

Figure 1. Graphs for Aneboda. Simulated mean annual pH (a, b); total dissolved $\mathrm{Al}(\mathbf{c}, \mathbf{d}), \mathrm{Ca}(\mathbf{e}, \mathbf{f}), \mathrm{Mg}(\mathbf{g}, \mathbf{h})$, and SO${ }_{4}^{2-}(\mathbf{i}, \mathbf{j})$; and sorbed $\mathrm{Ca}^{2+}(\mathbf{k}, \mathbf{l})$. Chemical dynamics in response to historic acidification $(\mathbf{a}, \mathbf{c}, \mathbf{e}, \mathbf{g}, \mathbf{i}, \mathbf{k})$ are presented above the response to harvesting events $(\mathbf{b}$, $\mathbf{d}, \mathbf{f}, \mathbf{h}, \mathbf{j}, \mathbf{l})$. The solid, dashed, and dotted lines represent the annual averages in the NH, CH, and WTH scenarios, respectively. The grey box spanning 1940 to 2000 represents the period of acidification due to S deposition. The symbols " $\times$ " and " $\bullet$ " represent the annual averages of empirical measurements in the $\mathrm{E}$ and $\mathrm{B}$ horizons, respectively.

pH sharply increased for 5-10 years before slowly declining over the remainder of the simulation (displayed in Figs. 3b, $4 \mathrm{~b}$, and $5 \mathrm{~b}$ ). The increase in $\mathrm{pH}$ immediately following a harvest event is primarily caused by mineralization of $\mathrm{BC}$ containing harvest residues (Fig. S3), but also marginally by a decreased dry $\mathrm{S}$ deposition. These processes increase the sorption of BCs on the exchange sites (Figs. 11, 21, and 31). The impact of harvesting on $\mathrm{pH}$ and sorbed $\mathrm{Ca}$ lasted for three to four decades at all three sites, eventually converging towards the NH scenario, before falling below it, which was demonstrated previously in long-term experiments (Zetterberg et al., 2016). However, once new stands have been es- tablished and trees begin to grow, uptake drives a net loss of $\mathrm{BCs}$ from the soil, leading to acidification. Across all three sites, the B1 horizons became the most acidified by 2080 compared to the $\mathrm{NH}$ scenario. The $\mathrm{O}$ horizon experienced the least change after harvesting events, and at Aneboda and Kindla the $\mathrm{pH}$ was slightly more basic compared to the $\mathrm{NH}$ scenario by 2080 . However, had the simulation been run for a longer time, it appears that the $\mathrm{pH}$ would eventually reach $\mathrm{NH}$ levels or drop below them. In reality a second harvest would likely have occurred after some 80-100 years, yielding a new period with a brief $\mathrm{pH}$ increase. 

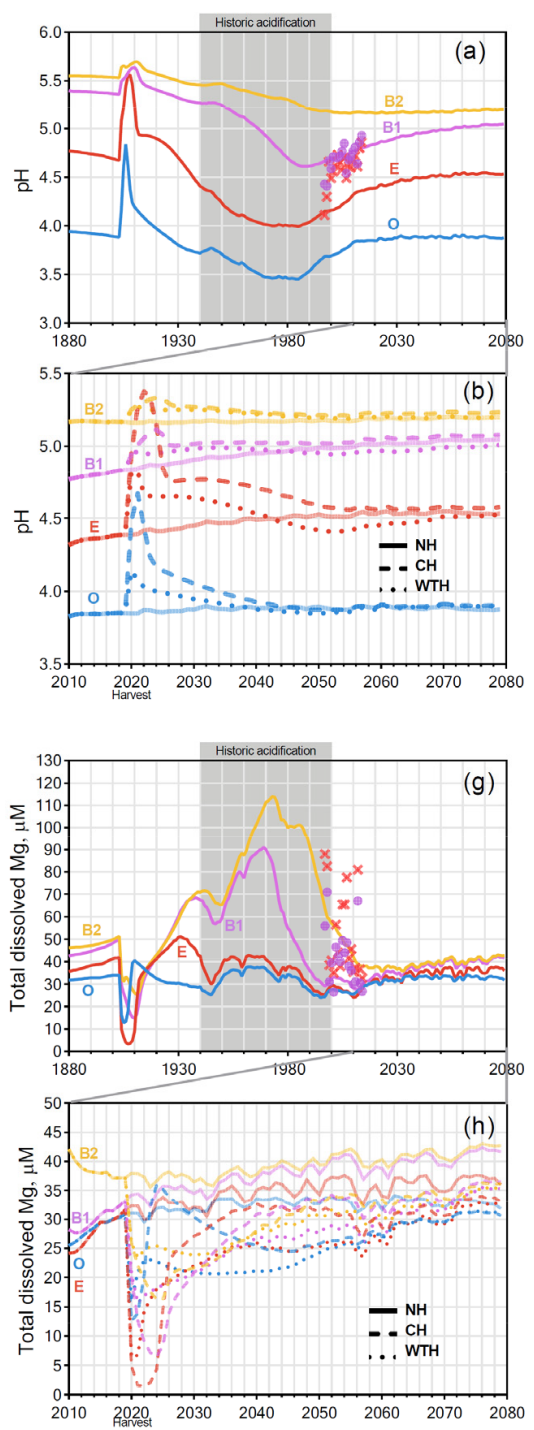
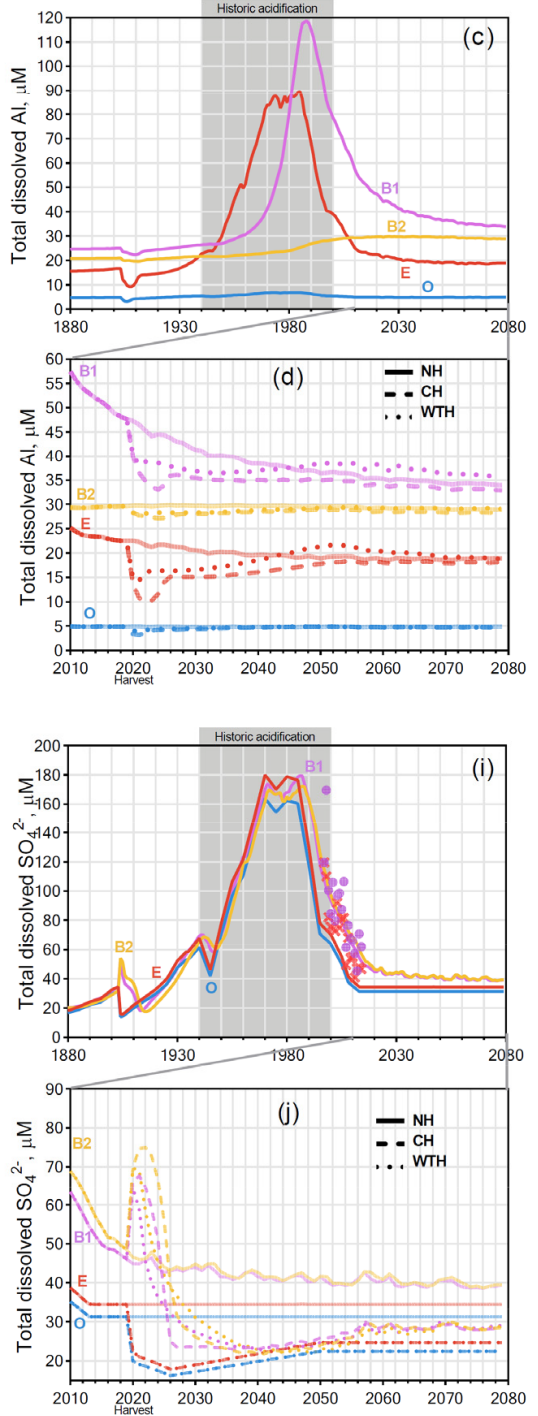
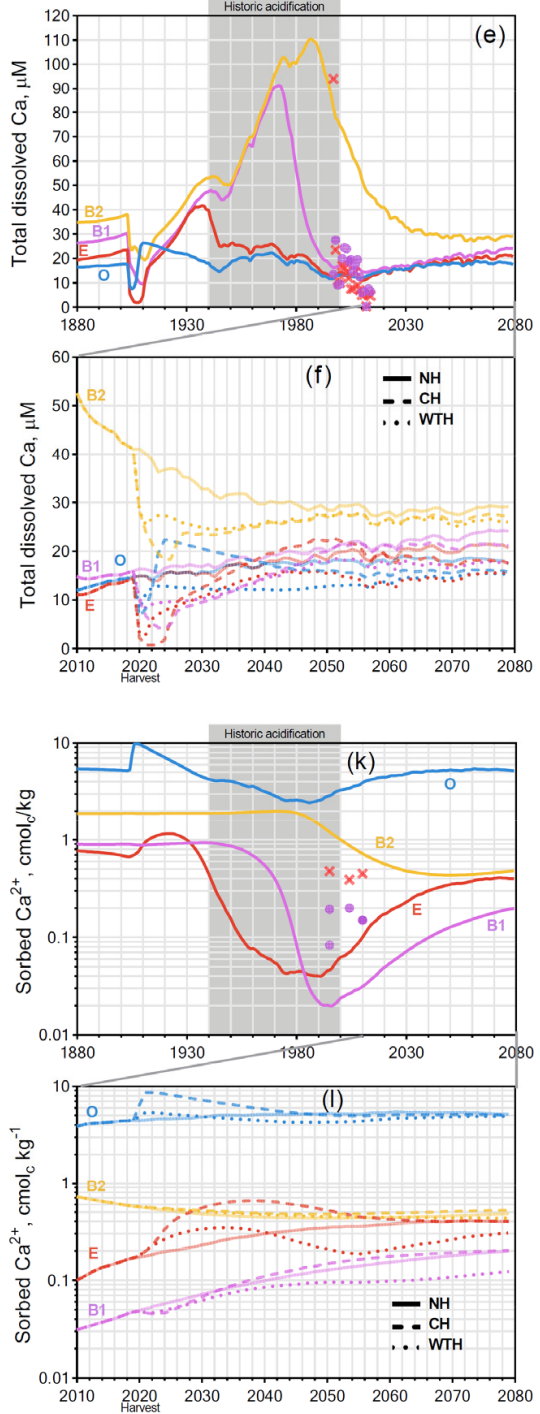

Figure 2. Graphs for Gårdsjön. Simulated mean annual pH (a, b); total dissolved $\mathrm{Al}(\mathbf{c}, \mathbf{d}), \mathrm{Ca}(\mathbf{e}, \mathbf{f}), \mathrm{Mg}(\mathbf{g}, \mathbf{h})$, and SO${ }_{4}^{2-}(\mathbf{i}, \mathbf{j})$; and sorbed $\mathrm{Ca}^{2+}(\mathbf{k}, \mathbf{l})$. Chemical dynamics in response to historic acidification $(\mathbf{a}, \mathbf{c}, \mathbf{e}, \mathbf{g}, \mathbf{i}, \mathbf{k})$ are presented above the response to harvesting events $(\mathbf{b}$, $\mathbf{d}, \mathbf{f}, \mathbf{h}, \mathbf{j}, \mathbf{l})$. The solid, dashed, and dotted lines represent the annual averages in the NH, CH, and WTH scenarios, respectively. The grey box spanning 1940 to 2000 represents the period of acidification due to S deposition. The symbols " $\times$ " and "•" represent the annual averages of empirical measurements in the $\mathrm{E}$ and $\mathrm{B}$ horizons, respectively.

Comparing the two harvesting scenarios demonstrates that over the 60-year time frame studied, simulated WTH acidified the soil more than $\mathrm{CH}$, but not by much even though $100 \%$ of the harvest residues are assumed withdrawn at WTH. At Aneboda, the $\mathrm{pH}$ across all horizons dropped by an average $0.13(\mathrm{WTH})$ and 0.12 units $(\mathrm{CH})$ compared to the NH scenario by the year 2080. The difference between WTH and $\mathrm{CH}$ was more pronounced at Kindla, which saw a mean $\mathrm{pH}$ decrease across all horizons of $0.10(\mathrm{WTH})$ and $0.04(\mathrm{CH})$ units compared to the NH scenario by 2080 . The most sensitive horizon to harvesting at Aneboda was the B1 horizon, which dropped in pH by $0.42(\mathrm{WTH})$ and $0.36(\mathrm{CH})$ units compared to the NH scenario by the year 2080. Ane- boda's B1 horizon also experienced a significant loss of soluble $\mathrm{Ca}^{2+}$ after harvesting, decreasing by $65 \%$ (WTH) and $56 \%(\mathrm{CH})$ by 2080 compared to the NH control. However, on a percentage basis, Aneboda's E horizon experienced the most precipitous loss of soluble $\mathrm{Ca}^{2+}$ after harvesting, decreasing by $87 \%(\mathrm{WTH})$ and $86 \%(\mathrm{CH})$ by 2080 compared to the $\mathrm{NH}$ control. Similar trends were seen in sorbed $\mathrm{Ca}^{2+}$ concentrations at Aneboda by 2080. The E horizon experienced a $92 \%(\mathrm{WTH})$ and $91 \%(\mathrm{CH})$ decrease compared to the $\mathrm{NH}$ control, while the same figures for the B1 horizon were $83 \%$ and $75 \%$, respectively. Neither harvesting scenario appeared to have a tangible impact on the $\mathrm{Ca}^{2+}$ concentrations (soluble or sorbed) in the B2 horizon at Aneboda. 

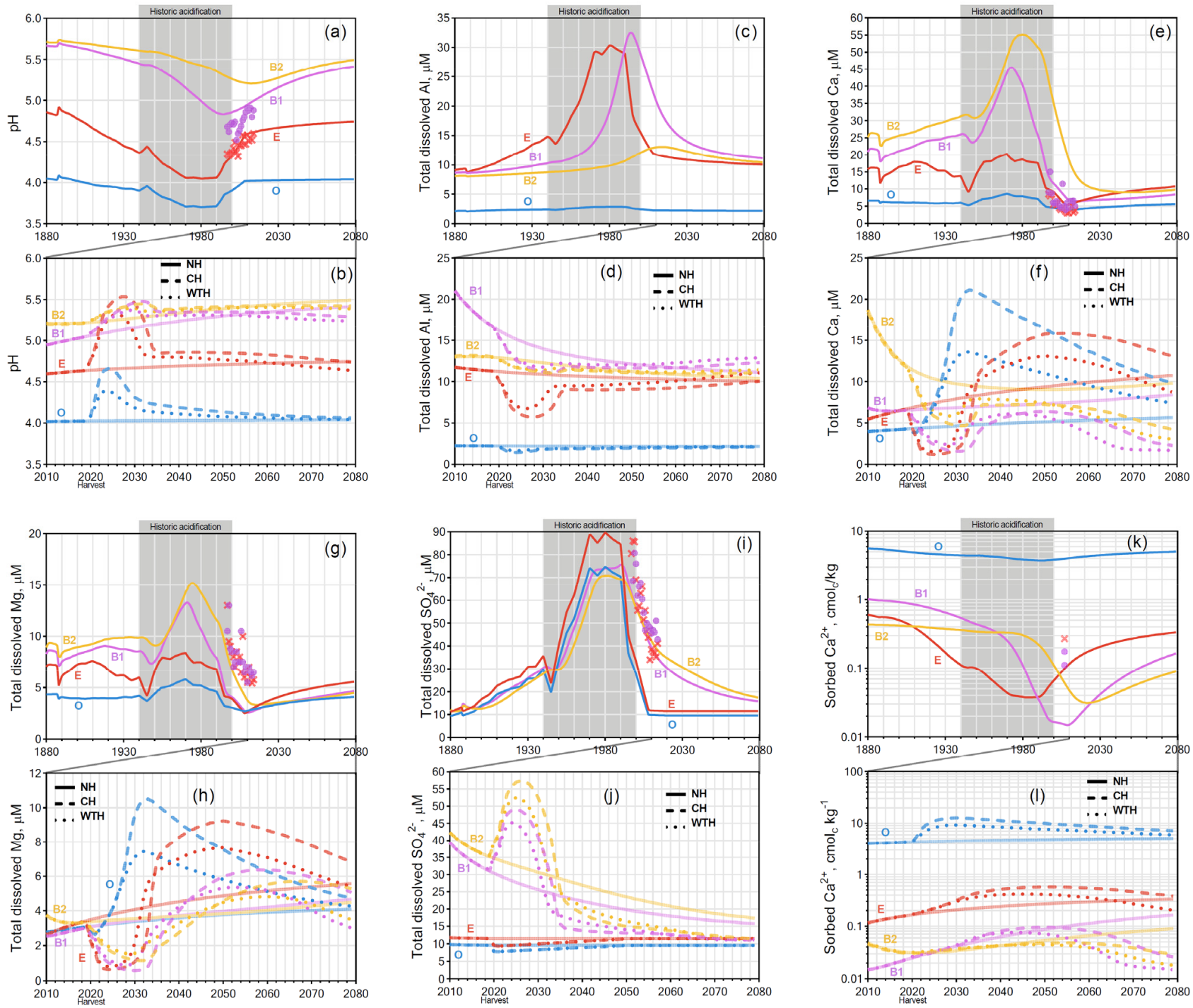

Figure 3. Graphs for Kindla. Simulated mean annual pH (a, b); total dissolved Al (c, d), Ca (e, f), $\mathrm{Mg}(\mathbf{g}, \mathbf{h})$, and $\mathrm{SO}_{4}^{2-}$ (i, j); and sorbed $\mathrm{Ca}^{2+}(\mathbf{k}, \mathbf{l})$. Chemical dynamics in response to historic acidification $(\mathbf{a}, \mathbf{c}, \mathbf{e}, \mathbf{g}, \mathbf{i}, \mathbf{k})$ are presented above the response to harvesting events $(\mathbf{b}$, $\mathbf{d}, \mathbf{f}, \mathbf{h}, \mathbf{j}, \mathbf{l})$. The solid, dashed, and dotted lines represent the annual averages in the NH, CH, and WTH scenarios, respectively. The grey box spanning 1940 to 2000 represents the period of acidification due to S deposition. The symbols " $\times$ " and " $\bullet$ " represent the annual averages of empirical measurements in the $\mathrm{E}$ and $\mathrm{B}$ horizons, respectively.

Contrary to the trends in $\mathrm{Ca}^{2+}$ concentrations in horizons $\mathrm{E}$, $\mathrm{B} 1$, and $\mathrm{B} 2$, after harvesting, the $\mathrm{O}$ horizon experienced an increase in soluble and sorbed $\mathrm{Ca}^{2+}$ by 2080 compared to the $\mathrm{NH}$ control.

Compared with the NH scenario, Kindla also experienced a phase with an increased $\mathrm{pH}$ followed by acidification at the end of the simulation period, but to a lesser degree than Aneboda. At Kindla, the mean soil pH at 2080 decreased by an average of 0.04 and 0.10 units after $\mathrm{CH}$ and $\mathrm{WTH}$, respectively. The B1 horizon was the most sensitive to acidification in both harvesting scenarios. Of the Kindla horizons, B1 also saw the greatest change in soluble and sorbed $\mathrm{Ca}^{2+}$ after harvesting. Soluble $\mathrm{Ca}^{2+}$ decreased by $80 \%$ (WTH) and $73 \%$
$(\mathrm{CH})$, while sorbed $\mathrm{Ca}^{2+}$ decreased $91 \%$ (WTH) and $84 \%$ (CH) by 2080 compared to the $\mathrm{NH}$ scenario. One interesting observation at Kindla was that the delayed acidification with increasing soil depth, which was related to $\mathrm{SO}_{4}^{2-}$ adsorption and desorption processes and historic acidification, was not observed after harvesting. Our simulations indicate that biological acidification did not initiate such processes, at least within 60 years after harvest, corresponding to an almost full rotation period.

A pH increase after harvesting was also observed at Gårdsjön, with the $\mathrm{O}$ and $\mathrm{E}$ horizons experiencing the strongest response. After increasing for a couple of years after harvest, the $\mathrm{pH}$ started to decline, slowly approaching the $\mathrm{NH}$ trend 

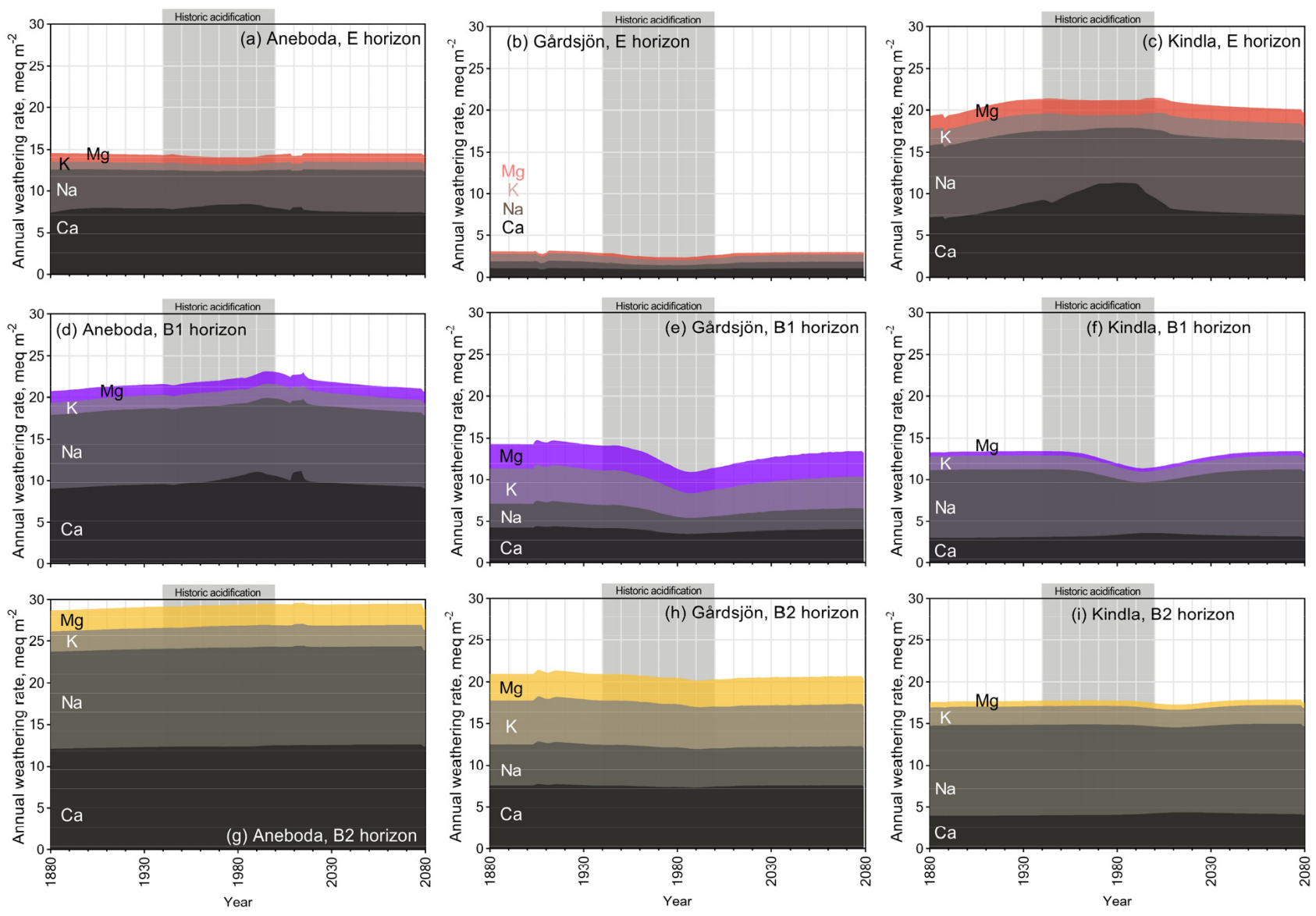

Figure 4. Stack plot of simulated base cation weathering rates in the NH scenario, with subdivisions of elemental components.

line. By the end of the simulation (2080), there was almost no difference between $\mathrm{CH}$, WTH, and the $\mathrm{NH}$ scenarios, and, contrary to the trends at Aneboda and Kindla, it did not appear that the soils were trending towards further acidification post-2080. This trend of disturbance immediately following a harvest before slowly approaching the $\mathrm{NH}$ trends can also be seen in $\mathrm{BC}$ concentrations. Total dissolved $\mathrm{Al}, \mathrm{Ca}$, and $\mathrm{Mg}$ sharply decreased immediately after $\mathrm{CH}$ and WTH for several years before meandering towards the $\mathrm{NH}$ trend line. However, by 2080, the concentration of soluble BCs after WTH was significantly lower than after $\mathrm{CH}$, and both harvesting events resulted in less soluble $\mathrm{BCs}$ compared to the $\mathrm{NH}$ scenario. Exchangeable $\mathrm{Ca}^{2+}$ concentrations following harvesting events at Gårdsjön appeared to oscillate around the NH trend line: increasing immediately after harvest (similar to Aneboda and Kindla), before slowly decreasing (also similar to Aneboda and Kindla), but then again increasing to approach the $\mathrm{NH}$ levels of sorbed $\mathrm{Ca}^{2+}$. There are several possible explanations for the $\mathrm{Ca}^{2+}$ profiles at Gårdsjön. First, Gårdsjön has a relatively high organic carbon content (Table 1), which governs the cation exchange capacity, resulting in higher exchangeable $\mathrm{Ca}^{2+}$ to buffer the soil pore water. Also, atmospheric deposition at Gårdsjön is signifi- cantly higher than at the other locations (Fig. S2), resulting in a higher-ionic-strength pore water, which would result in quicker transport of soluble ions between the horizons.

The absolute magnitude of the model-predicted changes is of course uncertain, not least in the light of the mixed success of the model to predict the available lysimeter data, as discussed in the previous section. Nevertheless, the simulated results strongly suggest that the acidification due to a harvesting event in 2020 would be less impactful, over the time range studied, than that of historic atmospheric acidification. Even though the $\mathrm{pH}$ in the WTH and $\mathrm{CH}$ scenario decreased with time as compared to the $\mathrm{NH}$ scenario, the simulated $\mathrm{pH}$ did not drop to the levels observed around the peak of historic acidification (1980-1990). As was discussed by Löfgren et al. (2017), this reflects the different acidification mechanisms involved. Most importantly, the concentration of mobile anions was much lower in the harvesting scenarios compared to the levels around the 1980s and 1990s, and this limits the potential $\mathrm{pH}$ decrease. 

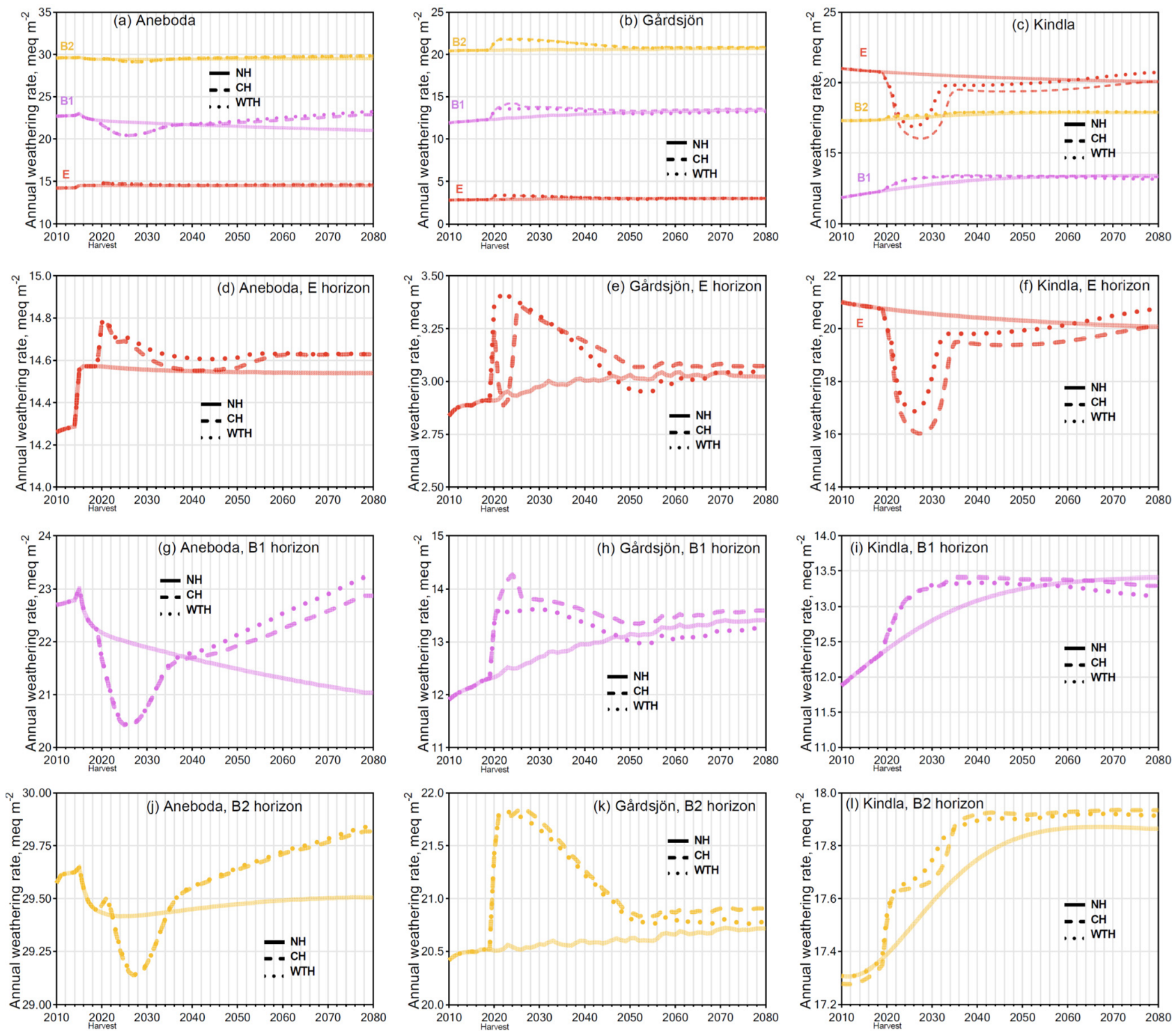

Figure 5. Simulated effects on base cation weathering rates in the conventional harvest $(\mathrm{CH})$, whole-tree harvest (WTH), and NH scenarios. The time series starts in 2010 just before harvest and the graphs are scaled in order to demonstrate differences between harvest intensities at the different sites and soil horizons.

\subsection{Weathering and release of base cations}

The weathering rates as calculated by the PROFILE submodel in HD-MINTEQ differed across locations and layers in response to historic acidification and the presence of weathering brakes such as $\mathrm{Ca}^{2+}$ and $\mathrm{Al}^{3+}$ (Eqs. 2 and 3). Across all sites and layers, the major BCs released by weathering were $\mathrm{Ca}^{2+}$ and $\mathrm{Na}^{+}$(Fig. 4). During the historic acidification period, the annual weathering rates at several sites and horizons (Aneboda: E; Gårdsjön: E, B1, and B2; Kindla: B1 and B2) actually decreased (Fig. S5), although not by much. This is due to the brakes in the weathering function (i.e. from $\mathrm{Al}^{3+}$ and BCs, Eqs. 2 and 3) and to the fact that total dissolved $\mathrm{Al}$ and $\mathrm{BCs}$ were much higher during this period
(Figs. 1, 2, and 3). In other words, the increased weathering rate expected from a decreased $\mathrm{pH}$ was offset by the increase in dissolved $\mathrm{Al}$ and $\mathrm{BCs}$, resulting in a very small net effect, which according to PROFILE was negative. However, the exact patterns varied from site to site and from layer to layer. The low weathering rates in the E horizon at Gårdsjön were likely due to its mineralogy; i.e. minerals other than quartz, $\mathrm{K}$ feldspar, and plagioclase were essentially absent from the E horizon, but they were present further down in the profile. Another factor leading to low weathering rates in the Gårdsjön $\mathrm{E}$ horizon was the relatively thin layer thickness.

Contrary to the decrease in weathering rates during the historic acidification of the 1970s, the simulated weather- 
ing rates after the harvesting scenarios in 2020 generally increased compared to NH by 2080 (Fig. 5) although, again, the net change was very small. However, the dynamics were quite different across each layer and site. The B1 horizon at Aneboda saw the strongest increase in weathering rates after harvesting, increasing by $9 \%(\mathrm{CH})$ and $11 \%$ (WTH) by 2080 compared to the NH scenario. The other horizons at Aneboda (E and B2) had almost unchanged weathering rates $(<2 \%$ increase by 2080 compared to a NH scenario). It is worth noting that the difference between harvesting events and $\mathrm{NH}$ at the Aneboda B1 and B2 horizons would likely continue to diverge beyond 2080. At Aneboda, by the year 2080, the sums of weathered BCs for the $\mathrm{CH}$ and WTH scenarios were $32 \mathrm{meqm}^{-2}(\mathrm{CH})$ and $46 \mathrm{meq} \mathrm{m}^{-2}$ (WTH) higher, respectively, than the BCs weathered in the NH scenario (Fig. S6). To put this into perspective, this difference is equivalent to only $1.1 \%$ and $1.7 \%$, respectively, of the atmospherically deposited BCs in the WTH plots over the same period. Such a small change in the weathering rate cannot be experimentally verified and is unlikely to be of any ecological significance.

The trends in simulated weathering rates at Gårdsjön after harvesting mimicked the trends seen in $\mathrm{pH}$; i.e. they rapidly increased for a couple of years, before declining to approach levels similar to the NH scenario. For all three layers at Gårdsjön, the modelled weathering rates appeared to reach steadystate conditions by the year 2055, whereas the weathering rates at Kindla and Aneboda deviated from the $\mathrm{NH}$ trend lines well into 2080. On a mass basis, CH and WTH at Gårdsjön resulted in amounts of weathered BCs that were 74 and 49 meq m$^{-2}$ higher than in the NH scenario by the year 2080 (Fig. S6). This change is equivalent to $0.6 \%$ and $0.4 \%$, respectively, of the sum of atmospherically deposited BCs in the WTH plots.

At Kindla, no horizon saw an increase in simulated weathering rate greater than $3.4 \%$ by 2080 , compared to the $\mathrm{NH}$ scenario. In fact, when weathering of the three mineral soil layers was summed, weathering rates slightly decreased by $0.9 \%(\mathrm{CH})$ and $2.0 \%(\mathrm{WTH})$ by 2080 compared to the $\mathrm{NH}$ scenario, which was equivalent to a decreased amount of weathered BCs of 64 and $26 \mathrm{meq}^{-2}$, respectively, over the simulated time period (Fig. S6). This result was influenced mainly by the large decrease in weathering rates in the $\mathrm{E}$ horizon in response to the $\mathrm{pH}$ increase after harvest (Fig. 3f), and the change is equivalent to $2.0 \%$ and $0.8 \%$ of the atmospherically deposited BCs.

Weathering is dictated by both $\mathrm{H}^{+}$(the lower the $\mathrm{pH}$, the more weathering) and by the weathering brakes in the model, most importantly dissolved $\mathrm{Al}^{3+}$ (the more $\mathrm{Al}^{3+}$, the less weathering). Some layers followed the generally expected trend of increased weathering rates with lower $\mathrm{pH}$ (B1 and B2 of Aneboda, and E of Kindla). These same layers were also low in dissolved $\mathrm{Al}^{3+}$ (Fig. S7), so the $\mathrm{Al}^{3+}$ weathering brake (the first terms of Eqs. 2 and 3) was not strong, and as a result the $\mathrm{H}^{+}$concentration dictated mineral weathering.
In all other layers ( $E$ of Aneboda, all horizons in Gårdsjön, and both $\mathrm{B}$ horizons of Kindla) the simulated weathering rates decreased with lower $\mathrm{pH}$, which was due to a relatively high concentration of dissolved $\mathrm{Al}^{3+}$ that caused the $\mathrm{Al}^{3+}$ weathering brake to be important. There is a certain threshold range in the model where the weathering brake due to $\mathrm{Al}^{3+}$ concentration started to influence weathering rates greatly, rendering $\mathrm{H}^{+}$concentration less important. The "weathering rate vs. Al" profiles in Fig. S7 show the transition from $\mathrm{pH}$ controlled weathering to Al-controlled weathering - weathering rates increase with increasing $\mathrm{Al}$ concentrations until a "break point" Al concentration is reached, where weathering rates begin to level off and decline. There are other weathering brakes as well, such as $\mathrm{Ca}^{2+}$, that limit the effect of $\mathrm{pH}$-induced weathering (Eq. 2), but these were less important. Although not obvious at first, the trends in simulated weathering rates within an individual layer were consistent, regardless of the source of acidification (be it acid rain or harvesting).

As mentioned previously, limitations in the model prevented us from addressing possible nitrification effects resulting from long-term $\mathrm{N}$ deposition, which may influence these results. A future task is to upgrade the HD-MINTEQ model to include $\mathrm{N}$ transformations, so that the effects arising from, for example, $\mathrm{N}$ deposition and nitrification can be more accurately assessed. Further, improved estimates of the mineralogical composition through, for example, X-ray diffraction would be desirable to avoid the mismatch in individual base cations, as was observed for $\mathrm{Mg}^{2+}$.

Although the model was parameterized for three Swedish forest sites, the main trends are likely to be valid also for forest soils in other parts of the world, i.e. that forest management practices are not likely to result in strong acidification effects within one full rotation period. However, these results should not be extrapolated to longer time perspectives, as certain drivers of the model may be increasingly uncertain with time. For example, it is not known to what extent the base cation uptake behaviour will differ between $\mathrm{NH}, \mathrm{CH}$, and WTH scenarios over a period of several rotations.

\section{Conclusions}

The HD-MINTEQ simulations for three sites indicate that forest harvesting contributes to long-term soil acidification, with marginally larger effects for whole-tree harvesting compared with stem-only harvesting scenarios. However, acidification due to harvesting events had much less impact on soil $\mathrm{pH}$ compared to historical acid rain, provided that harvesting did not cause substantial nitrification. The strongest effect of historic acid rain was seen at Gårdsjön, the site that experienced the most sulfuric-acid deposition. Furthermore, our model results suggest that the $\mathrm{BC}$ weathering rates remained largely unchanged during the historic acidification era, as a 
result of the opposing effects of decreased $\mathrm{pH}$ and increased levels of dissolved $\mathrm{Al}^{3+}$.

Although the predicted long-term $\mathrm{pH}$ effect of harvesting is predicted to be small in relation to historical acidification, future harvesting simulations did significantly change the soil chemistry compared to a no-harvest scenario. Directly after a harvest, modelled soil solution $\mathrm{pH}$ increased and remained above the $\mathrm{NH}$ baseline for several decades before eventually dropping below the baseline. Mineralization of harvest residues, which release base cations, and a decreased dry sulfur deposition were likely responsible for the alkalization immediately following a harvesting event. As in the case of historical acidification, the $\mathrm{BC}$ weathering rates were little affected by harvesting. Over a period of 60 years after simulated harvest events, there were very small increases in the $\mathrm{BC}$ weathering rates as compared to the noharvest simulation for the Aneboda and Gårdsjön sites, assuming that the PROFILE weathering submodel is correct. Over the same time period, Kindla saw a very small decrease in $\mathrm{BC}$ weathering.

Code and data availability. The raw data, the metadata, and data processing codes are stored on data servers and repositories and are available upon request to the corresponding authors.

Supplement. The supplement related to this article is available online at: https://doi.org/10.5194/soil-5-63-2019-supplement.

Author contributions. SL, JPG, and EMG conceived the idea. JPG prepared the HD-MINTEQ code. SL reviewed and prepared the available soil chemical data for all sites. SB supplied estimates for the net BC uptake at Gårdsjön, whereas TZ supplied BC uptake data for the two other sites. EMG performed all the computer simulations, analysed the results, prepared all tables and figures, and wrote the first version of the manuscript. All authors commented on and edited the paper.

Competing interests. The authors declare that they have no conflict of interest.

Special issue statement. This article is part of the special issue "Quantifying weathering rates for sustainable forestry (BG/SOIL inter-journal SI)". It is not associated with a conference.

Acknowledgements. This study was funded by the Swedish Research Council Formas (reg. no. 2011-1691) within the strong research environment Quantifying Weathering Rates for Sustainable Forestry (QWARTS) and by the Swedish Energy Agency (project no. 31708-3). Carin Sjöstedt is acknowledged for help with the uptake scenarios.
Edited by: Boris Jansen

Reviewed by: three anonymous referees

\section{References}

Akselsson, C., Westling, O., Sverdrup, H., Holmqvist, J., Thelin, G., Uggla, E., and Malm, G.: Impact of harvest intensity on longterm base cation budgets in Swedish forest soils, Water Air Soil Pollut. Focus, 7, 201-210, https://doi.org/10.1007/978-1-40205885-1_22, 2007.

Belyazid, S. and Moldan, F.: Using ForSAFE-Veg to investigate the feasibility and requirements of setting critical loads for $\mathrm{N}$ based on vegetation change - pilot study at Gårdsjön. IVL report B1875, Gothenburg, Sweden, 2009.

Belyazid, S., Westling, O., and Sverdrup, H.: Modelling changes in forest soil chemistry at 16 Swedish coniferous forest sites following deposition reduction, Environ. Pollut., 144, 596-609, https://doi.org/10.1016/j.envpol.2006.01.018, 2006.

Bertills, U., Fölster, J., and Lager, H.: Natural acidification only report on in-depth evaluation of the environmental quality objective work, Report 5766, Swedish Environmental Protection Agency, Stockholm, Sweden, 2007.

Casetou-Gustafson, S., Hillier, S., Akselsson, C., Simonsson, M., Stendahl, J., and Olsson, B. A.: Comparison of measured (XRPD) and modeled (A2M) soil mineralogies: a study of some Swedish forest soils in the context of weathering rate predictions, Geoderma, 310, 77-88, https://doi.org/10.1016/j.geoderma.2017.09.004, 2018.

Cosby, B. J., Hornberger, G. M., Galloway, J. N., and Wright, R. E.: Time scales of catchment acidification. A quantitative model for estimating freshwater acidification, Environ. Sci. Technol., 19, 1144-1149, https://doi.org/10.1021/es00142a001, 1985.

Cosby, B. J., Hornberger, G. M., Wright, R. F., and Galloway, J. N.: Modeling the effects of acid deposition: control of long-term sulfate dynamics by soil sulfate adsorption, Water Resour. Res., 22, 1283-1291, https://doi.org/10.1111/j.16000536.2012.02097.x, 1986.

Cosby, B. J., Ferrier, R. C., Jenkins, A., and Wright, R. F.: Modelling the effects of acid deposition: refinements, adjustments and inclusion of nitrogen dynamics in the MAGIC model, Hydrol. Earth Syst. Sci., 5, 499-518, https://doi.org/10.5194/hess-5-4992001, 2001.

de Jong, J., Akselsson, C., Egnell, G., Löfgren, S., and Olsson, B. A.: Realizing the energy potential of forest biomass in Sweden How much is environmentally sustainable?, For. Ecol. Manage., 383, 3-16, https://doi.org/10.1016/j.foreco.2016.06.028, 2017.

Ekö, P. M.: A growth simulator for Swedish forests, based on data from the national forest survey. Report 16, Department of Silviculture, Swedish University of Agricultural Sciences, Umeå, Sweden, 1985.

Engardt, M., Simpson, D., Schwikowski, M., and Granat, L.: Deposition of sulphur and nitrogen in Europe 1900-2050. Model calculations and comparison to historical observations, Tellus B, 69, 1328945, https://doi.org/10.1080/16000889.2017.1328945, 2017.

Ferm, M. and Hultberg, H.: Method to estimate atmospheric deposition of base cations in coniferous throughfall, Water. Air. Soil Pollut., 85, 2229-2234, https://doi.org/10.1007/BF01186165, 1995. 
Ferm, M. and Hultberg, H.: Dry deposition and internal circulation of nitrogen, sulphur and base cations to a coniferous forest, Atmos. Environ., 33, 4421-4430, https://doi.org/10.1016/S13522310(99)00211-3, 1999.

Futter, M. N., Ring, E., Högbom, L., Entenmann, S., and Bishop, K. H.: Consequences of nitrate leaching following stem-only harvesting of Swedish forests are dependent on spatial scale, Environ. Pollut., 158, 3552-3559, https://doi.org/10.1016/j.envpol.2010.08.016, 2010.

Gustafsson, J. P.: Modeling the Acid-Base Properties and Metal Complexation of Humic Substances with the Stockholm Humic Model, J. Colloid Interface Sci., 244, 102-112, https://doi.org/10.1006/jcis.2001.7871, 2001.

Gustafsson, J. P.: Visual MINTEQ, version 3.1, available at: https: //vminteq.lwr.kth.se (last access: 1 February 2019), 2018.

Gustafsson, J. P. and Kleja, D. B.: Modeling salt-dependent proton binding by organic soils with the NICA-Donnan and Stockholm Humic models, Environ. Sci. Technol., 39, 5372-5377, https://doi.org/10.1021/es0503332, 2005.

Gustafsson, J. P., Bhattacharya, P., Bain, D. C., Fraser, A. R., and McHardy, W. J.: Podzolisation mechanisms and the synthesis of imogolite in northern Scandinavia, Geoderma, 66, 167-184, https://doi.org/10.1016/0016-7061(95)00005-9, 1995.

Gustafsson, J. P., Akram, M., and Tiberg, C.: Predicting sulphate adsorption/desorption in forest soils: Evaluation of an extended Freundlich equation, Chemosphere, 119, 83-89, https://doi.org/10.1016/j.chemosphere.2014.05.067, 2015.

Gustafsson, J. P., Belyazid, S., McGivney, E., and Löfgren, S.: Aluminium and base cation chemistry in dynamic acidification models - need for a reappraisal?, SOIL, 4, 237-250, https://doi.org/10.5194/soil-4-237-2018, 2018.

Högberg, P., Näsholm, T., Franklin, O., and Högberg, M. N.: Tamm Review: On the nature of the nitrogen limitation to plant growth in Fennoscandian boreal forests, For. Ecol. Manage., 403, 161185, https://doi.org/10.1016/j.foreco.2017.04.045, 2017.

Iwald, J., Löfgren, S., Stendahl, J., and Karltun, E.: Acidifying effect of removal of tree stumps and logging residues as compared to atmospheric deposition, For. Ecol. Manage., 290, 49-58, https://doi.org/10.1016/j.foreco.2012.06.022, 2013.

Karltun, E.: Acidification of forest soils on glacial till in Sweden. Soil chemical status and acidification processes in relation to environmental conditions, Report 4427, Swedish Environmental Protection Agency, Stockholm, Sweden, 1995.

Karltun, E., Bain, D. C., Gustafsson, J. P., Mannerkoski, H., Murad, E., Wagner, U., Fraser, A. R., McHardy, W. J., and Starr, M.: Surface reactivity of poorly-ordered minerals in podzol B horizons, Geoderma, 94, 265-288, https://doi.org/10.1016/S00167061(98)00141-4, 2000.

Löfgren, S., Bringmark, L., Aastrup, M., Hultberg, H., Kindbom, K., and Kvarnäs, H.: Sulphur balances and dynamics in three forested catchments in Sweden, Water Air Soil Pollut., 130, 631636, https://doi.org/10.1023/a:1013840309681, 2001.

Löfgren, S., Gustafsson, J. P., and Bringmark, L.: Decreasing DOC trends in soil solution along the hillslopes at two IM sites in southern Sweden - geochemical modeling of organic matter solubility during acidification recovery, Sci. Total Environ., 409, 201-210, https://doi.org/10.1016/j.scitotenv.2010.09.023, 2010.

Löfgren, S., Aastrup, M., Bringmark, L., Hultberg, H., LewinPihlblad, L., Lundin, L., Karlsson, G. P., and Thunholm, B.: Re- covery of soil water, groundwater, and streamwater from acidification at the swedish integrated monitoring catchments, Ambio, 40, 836-856, https://doi.org/10.1007/s13280-011-0207-8, 2011.

Löfgren, S., Grandin, U., and Stendera, S.: Long-term effects on nitrogen and benthic fauna of extreme weather events: Examples from two Swedish headwater streams, Ambio, 43, 58-76, https://doi.org/10.1007/s13280-014-0562-3, 2014.

Löfgren, S., Ågren, A., Gustafsson, J. P., Olsson, B. A., and Zetterberg, T.: Impact of whole-tree harvest on soil and stream water acidity in southern Sweden based on HD-MINTEQ simulations and pH-sensitivity, For. Ecol. Manage., 383, 49-60, https://doi.org/10.1016/j.foreco.2016.07.018, 2017.

Martinson, L., Alveteg, M., Mörth, C.-M., and Warfvinge, P.: The effect of changes in natural and anthropogenic deposition on modelling recovery from acidification, Hydrol. Earth Syst. Sci., 7, 766-776, https://doi.org/10.5194/hess-7-766-2003, 2003.

Nilsson, B., Nilsson, D., and Thörnqvist, T.: Distributions and losses of logging residues at clear-felled areas during extraction for bioenergy: comparing dry- and fresh-stacked method, Forests, 6, 4212-4227, https://doi.org/10.3390/f6114212, 2015.

Nilsson, S. I., Miller, H. G., and Miller, J. D.: Forest growth as a possible cause of soil and water acidification: an examination of the concepts, Oikos, 39, 40-49, https://doi.org/10.2307/3544529, 1982.

Nilsson, T. and Lundin, L.: Uppskattning av volymvikten i svenska skogsjordar från halten organiskt kol och markdjup, Report 91, Department of Forest Soils, Swedish University of Agricultural Sciences, Uppsala, Sweden, 2006 (in Swedish).

Posch, M. and Kurz, D.: A2M-A program to compute all possible mineral modes from geochemical analyses, Comput. Geosci., 33, 563-572, https://doi.org/10.1016/j.cageo.2006.08.007, 2007.

Sverdrup, H.: Geochemistry, the key to understanding environmental chemistry, Sci. Total Environ., 183, 67-87, https://doi.org/10.1016/0048-9697(95)04978-9, 1996.

Sverdrup, H. and De Vries, W.: Calculation critical loads for acidity with the Simple Mass Balance method, Water Air Soil Pollut., 72, 143-162, https://doi.org/10.1007/BF01257121, 1994.

Sverdrup, H. and Warfvinge, P.: Calculating field weathering rates using a mechanistic geochemical model PROFILE, Appl. Geochem., 8, 273-283, https://doi.org/10.1016/08832927(93)90042-F, 1993.

Vadeboncoeur, M. A., Hamburg, S. P., Yanai, R. D., and Blum, J. D.: Rates of sustainable forest harvest depend on rotation length and weathering of soil minerals, For. Ecol. Manage., 318, 194-205, https://doi.org/10.1016/j.foreco.2014.01.012, 2014.

van Breemen, N., Driscoll, C. T., and Mulder, J.: Acidic deposition and internal proton sources in acidification of soils and waters, Nature, 307, 599-604, https://doi.org/10.1038/307599a0, 1984.

Wallman, P., Svensson, M. G. E., Sverdrup, H., and Belyazid, S.: ForSAFE - An integrated process-oriented forest model for longterm sustainability assessments, For. Ecol. Manage., 207, 19-36, https://doi.org/10.1016/j.foreco.2004.10.016, 2005.

Warfvinge, P., Falkengren-Grerup, U., Sverdrup, H., and Andersen, B.: Modelling long-term cation supply in acidified forest stands, Environ. Pollut., 80, 209-221, https://doi.org/10.1016/02697491(93)90041-L, 1993.

Zetterberg, T., Köhler, S. J., and Löfgren, S.: Sensitivity analyses of MAGIC modelled predictions of future impacts of whole-tree harvest on soil calcium supply and stream acid 
neutralizing capacity, Sci. Total Environ., 494-495, 187-201, https://doi.org/10.1016/j.scitotenv.2014.06.114, 2014.
Zetterberg, T., Olsson, B. A., Löfgren, S., Hyvönen, R., and Brandtberg, P. O.: Long-term soil calcium depletion after conventional and whole-tree harvest, For. Ecol. Manage., 369, 102-115, https://doi.org/10.1016/j.foreco.2016.03.027, 2016. 